\title{
Reporting Adverse Drug Reactions: Evaluation of Knowledge, Attitude and Practice among Community Pharmacists in UAE
}

\author{
Sundos Qassim ${ }^{1}$, Zakia Metwaly ${ }^{2}$, Mohammed Shamsain ${ }^{3}$, Yassin Al Hariri ${ }^{1}$ \\ ${ }^{1}$ Lecturer, Clinical Pharmacy and Pharmacy Practice Department, \\ ${ }^{2}$ Professor, Pharmacology and Microbiology Department \\ 3 Associate Professor, Clinical Pharmacy and Pharmacy Practice Department \\ Pharmacy College, Ajman University of Science and Technology Network, Ajman, United Arab Emirates.
}

\begin{abstract}
In United Arab Emirates (UAE), the pharmacovigilance (PV) program is in the stage of initiation therefore the success of such a program depends upon the participation of the health care professionals. No study has been found regarding the role of the community pharmacist as a health care provider in monitoring drug safety after marketing. This study aimed to evaluate the knowledge, attitudes and practice (KAP) toward adverse drug reactions (ADRs) reporting among community pharmacists (CPS) in Ajman and Sharjah, UAE. Evaluating the baseline KAP of the CPs regarding ADRs reporting can be useful in providing information for the progress of a PV program in UAE. An interview questionnaire was delivered to 300 CPs in Ajman and Sharjah cities. Statistical Package for the Social Sciences (SPSS) version 20 was used for data analysis. Only $4.9 \%$ of respondents had good ADRs reporting knowledge, while the majority of pharmacists $93.7 \%$ had a positive attitude towards ADRs reporting. Forty four percent of the pharmacists were not alert about ADRs reporting program in UAE. Only $3.6 \%$ of the enrolled pharmacists submitted ADRs report and only $11.2 \%$ had good practice score. The results of our study clearly point out that in spite of the community pharmacists positive attitude there was a lack of appropriate knowledge and practice to implement ADRs reporting successfully. The results emphasized the critical need for interventions to support ADRs reporting activity and to maintain CPs positive attitude.
\end{abstract}

KEYWORDS - Adverse Drug Reaction (ADRs), Attitude, Community Pharmacists, Knowledge, Pharmacovigilance, Practice, Reporting.

\section{INTRODUCTION}

The Adverse drug reactions (ADRs) are a cause of morbidity and mortality [1-3]. Moreover, ADRs are one of the causing factors for hospital admissions [4-6]. It had been found that the incidence of ADRs induced hospital admissions is $6.7 \%$ of all medical admissions [7]. Huge economic loss have been associated with ADRs [7-9]. Not all ADRs can be recognized from early safety studies done by the manufacturer, so it is very important to monitor ADRs after marketing [3,10]. The tragedy of the Thalidomide disaster has encouraged many countries to establish Pharmacovigilance (PV) systems for detecting ADRs of drugs available in the market [11].

Spontaneous reporting systems are considered the main mechanism of PV system to gather information about ADRs after the drug released into the market [12]. Under reporting of ADRs is a major obstacle for the progress of PV programs [13]. Researches from different countries all over the world found a strong association between ADRs reporting and knowledge, attitude and practice (KAP) of the health care professional [3, 14-18]. Thus improving the KAP of health care professional is essential for establishing and improving PV program in any country $[19,20]$. Community pharmacists (CPs) are important source of ADRs reporting because of the fact that they are the first to be contacted by patients in most ADRs cases [2].

However, no study has been found regarding the role of CPs as ADRs reporters in UAE. Even though, the pharmacists has an immense responsibility in strengthening PV system [2, 21]. Knowledge of pharmacists on ADRs reporting was found to be inconsistent. Several studies had shown low level of knowledge [22] while others attributed a good knowledge level [23]. Several studies had shown that health care professionals were having the needed information on how to find out ADRs but they don't know where to send ADRs reports [ 2426]. Attitudes on ADRs reporting were not rated in the same level among health care professionals. Some studies revealed positive attitudes [25, 26] while other studies reported negative attitudes [22, 27].

STUDY OBJECTIVES: To determine the knowledge, attitudes and practice and the association between knowledge, attitudes and practice among UAE CPs toward ADRs reporting. 


\section{MATERIALS AND METHODS}

A cross- sectional study was conducted using multistage sampling method, convenience and simple random sampling were applied respectively. The KAP questionnaire was designed based on the parameters to be evaluated as part of the study and by referring to previous literature [16, 19]. Modifications were done to make it convenient for UAE CPs. The developed questionnaire was designed to be interview-administrated. The questionnaire compromised of 4 parts: social- demographic, knowledge, attitude and practice. The minimum sample size was calculated using Raosoft sample size calculator (218) [28]. The final chosen sample size was 300 to overcome non response and to avoid decreased sample size than minimum.

Face validity was done by university lecturers and experts. Ten pharmacists enrolled in a pilot study to examine the survey reliability, determine the time needed for data collection and to revise and finalize the questionnaire. The registered licensed Cps working in Ajman and Sharjah in 2013, males and females who were willing to participate were included in the study. Community pharmacists who were not willing to participate, on leave during the study and unlicensed or unregistered were excluded from the study.

One pharmacist was selected from each pharmacy. The selection was done at the same time of the visit by inviting the available licensed community pharmacist. Pharmacists who were willing to be enrolled in this study were asked to sign informed consent forms. No attempt was made to prompt the respondents by suggesting answers directly.

DATA ANALYSIS: All questions were coded and then imported to SPSS version 20 for analysis. Descriptive analysis was used to analyze the socio-demographic data. A correlation analysis was performed to test association. $\mathrm{P}$ value of less than 0.05 was considered significant.

\section{RESULTS}

The response rate was $74.3 \%$ in which the total number of usable data was 223 . The sociodemographic characteristic of the enrolled pharmacists are listed in Table (1).

Table 1: Social demographic data of the respondents

\begin{tabular}{|l|c|c|c|}
\hline Variables & Sub groups & Frequency & Percentage \\
\hline Age & $22-30$ & 83 & 37.2 \\
& $31-40$ & 80 & 35.9 \\
& $41-50$ & 43 & 19.3 \\
& 51 or over & 17 & 7.6 \\
\hline Nationality & South Eastern Asia & 88 & 39.5 \\
& Arab & 103 & 46.2 \\
\hline Graduation year from pharmacy college & Others & 32 & 14.3 \\
\hline Post graduate certificate & $<5$ years & 66 & 27.4 \\
& $5-10$ years & 96 & 43.0 \\
\hline Type of postgraduate certificate & $>10$ years & 24 & 10.8 \\
& Yes & 199 & 89.2 \\
\hline Experience years & No & 2 & 0.9 \\
& Diploma & 21 & 9.4 \\
& Master & 2 & 0.9 \\
\hline Number of prescription dispensed per day & PhD & 65 & 29.1 \\
& $<5$ years & 96 & 29.6 \\
& $5-10$ & 90 & 41.3 \\
\hline Number of patient served per day & $>10$ years & 54 & 40.4 \\
& $<20$ & 79 & 24.2 \\
\hline Time spent with patient & $21-30$ & 21 & 35.4 \\
\hline
\end{tabular}

Eleven (4.9\%) of the respondents had a good knowledge score while $212(95.1 \%)$ had poor knowledge score (Table 2). 
Table 2: Responses to the knowledge related questions

\begin{tabular}{|c|c|c|}
\hline \multicolumn{3}{|l|}{ Good Knowledge } \\
\hline Questions & Frequency & Percentage \\
\hline 1. Are you aware of any ADRs reporting program in United Arab Emirates (UAE)? & 124 & 55.9 \\
\hline 2. Do you consider ADRs reporting as a natural task for a pharmacist? & 176 & 78.9 \\
\hline $\begin{array}{l}\text { 3. Is it possible for a community pharmacist in UAE to report ADRs to the Ministry of Health } \\
(\mathrm{MOH}) \text { ? }\end{array}$ & 118 & 52.9 \\
\hline 4. Are you familiar with the term Pharmacovigilance? & 59 & 26.5 \\
\hline 5. If yes, please dene the term Pharmacovigilance? & 44 & 19.7 \\
\hline 6. What do you understand by the term ADR? & 0.0 & 0.0 \\
\hline $\begin{array}{l}\text { 7. Do you know the difference between Adverse Drug Reaction type } 1 \text { and Adverse Drug } \\
\text { Reaction type } 2 \text { ? }\end{array}$ & 28 & 12.6 \\
\hline 8. If yes, please define? & 15 & 6.7 \\
\hline 9. Do you know how to report an ADR? & 37 & 16.6 \\
\hline 10. Do you know that only proven ADR for an old drug should be reported to MOH? & 21.1 & 47 \\
\hline $\begin{array}{l}\text { 11. There is no need to report the reactions related to Over the Counter products or herbal } \\
\text { products in UAE. }\end{array}$ & 115 & 51.6 \\
\hline 13. Do you know in which country the international center for ADR monitoring is located? & 21 & 9.4 \\
\hline 14. If Yes, specify. & 6 & 2.7 \\
\hline 15. Do you know the name of the scale used to establish the causality of ADR? & 5 & 2.2 \\
\hline 16. If yes, please specify. & 1 & 0.4 \\
\hline 17. Do you know the name of the scale used to establish severity of ADR? & 2 & 0.9 \\
\hline 18. If yes, please specify. & 0.0 & 0.0 \\
\hline 19. Which one of the following drugs is known to cause fatal anaphylaxis reaction? & 162 & 72.6 \\
\hline 20. Type I hypersensitivity reactions can be prevented by which of the followings? & 194 & 87.0 \\
\hline
\end{tabular}

Ninety three percent (209) had positive attitude score while $6.3 \%$ (14) had negative attitude score. For positive attitude items, where pharmacists should have, the percentage ranged from $84.8 \%$ to $95.1 \%$. While for the negative attitude items, where pharmacists should not have, the percentage ranged from $1.3 \%$ to $39.9 \%$ (Table 3 ).

Table 3: Responses to the attitude related questions

\begin{tabular}{|c|c|c|}
\hline \multicolumn{3}{|l|}{ Positive attitude $^{\text {a }}$} \\
\hline Questions & Frequency & Percentage \\
\hline 1. Community pharmacist should be involved in ADRs reporting process. ${ }^{p}$ & 193 & 86.5 \\
\hline $\begin{array}{l}\text { 2. It is important for community pharmacist to attend training programs in } \\
\text { pharmacovigilance. }\end{array}$ & 192 & 86.1 \\
\hline 3. Reporting ADRs is part of the professional role of a pharmacist. ${ }^{\mathrm{P}}$ & 199 & 89.2 \\
\hline 4. I believe that the monitoring drug safety is important. ${ }^{\mathrm{P}}$ & 208 & 93.3 \\
\hline 5. It should be confirmed that ADR is related to the drug before reporting. ${ }^{n}$ & 6 & 2.7 \\
\hline 6. It is not necessary to report ADRs of OTC products supplied by my pharmacy. ${ }^{n}$ & 89 & 39.9 \\
\hline 7. It is important to report ADRs leading to hospitalization. ${ }^{\mathrm{P}}$ & 205 & 91.9 \\
\hline 8. It is important to report ADRs leading to a life threatening situations. ${ }^{p}$ & 212 & 95.1 \\
\hline 9. It is important to report ADRs leading to congenital abnormality. ${ }^{\mathrm{P}}$ & 209 & 93.7 \\
\hline 10. It is important to report ADRs leading to persistent disability or incapacity. ${ }^{P}$ & 204 & 91.5 \\
\hline 11. It is important to report ADRs leading to patients death. ${ }^{\mathrm{P}}$ & 210 & 94.2 \\
\hline $\begin{array}{l}\text { 12. It is important to report ADRs in order to answer the questions that may arise in my } \\
\text { practice. }\end{array}$ & 3 & 1.3 \\
\hline 13. Reporting of ADRs is important to show patients that their concerns are taken seriously. ${ }^{\mathrm{P}}$ & 204 & 91.5 \\
\hline 14. Reporting ADRs is part of pharmaceutical care process. ${ }^{\mathrm{P}}$ & 206 & 92.4 \\
\hline 15. Consulting the physician is important before reporting an ADR. ${ }^{\mathrm{n}}$ & 7 & 3.1 \\
\hline 16. It is important to discuss ADRs with pharmacologist and/or university lecturer. ${ }^{\mathrm{P}}$ & 189 & 84.8 \\
\hline $\begin{array}{l}\text { : Proportion positive attitude who answer agree for attitude that they should have and disas } \\
\text { not have. } \\
\text { p: positive attitude item. } \\
{ }^{n}: \text { negative attitude item. }\end{array}$ & e for attitude & at they should \\
\hline
\end{tabular}

Twenty five (11\%) of participants had good practice score while $198(88.8 \%)$ had low practice score in which only $8(3.6 \%)$ of the participants had sent suspected ADRs reports to Ministry of Health (MOH) or manufacture companies (Table 4). 
Table 4: Responses to the practice related questions

\begin{tabular}{|c|c|c|}
\hline \multicolumn{3}{|l|}{ Answering yes response } \\
\hline Questions & Frequency & Percentage \\
\hline 1. Have you ever diagnosed an ADRs within the last 12 months? & 64 & 28.7 \\
\hline 2. Have you ever sent a suspected ADR report to MOH or manufacturer? & 8 & 3.6 \\
\hline $\begin{array}{l}\text { 3. Have you ever reported any ADRs related to OTC or herbal products in the last } \\
12 \text { months? }\end{array}$ & 6 & 2.7 \\
\hline $\begin{array}{l}\text { 4. Have you ever reported a new ADR (not mentioned in drug leaflet) for any } \\
\text { drug? }\end{array}$ & 2 & 0.9 \\
\hline 5. Have you ever prevent any serious ADRs? & 100 & 44.8 \\
\hline 6. Have you read an article related to ADRs in the last 12 months? & 103 & 46.2 \\
\hline 7. Have you ever counselled patient regarding ADRs in the last 12 months? & 175 & 78.5 \\
\hline $\begin{array}{l}\text { 8. Have you ever counselled patient regarding food /drug interaction in the last } 12 \\
\text { months? }\end{array}$ & 196 & 87.9 \\
\hline
\end{tabular}

There was a positive correlation between knowledge and attitude ( $r h o=0.141, \mathrm{p}<0.05$ ) and between knowledge and practice $(\mathrm{r}=0.171, \mathrm{p}<0.001)$. There was no association between attitude and practice.

\section{DISCUSSION}

This is the first study of its kind in the UAE that evaluated the KAP of the CPs regarding PV and ADRs reporting. What was evident from the present study is that there are gross problems with reporting ADRs by the UAE CPs. The study outcomes revealed that CPs had poor knowledge towards ADRs reporting and PV activity, which is compatible with previous studies $[16,29,30]$.

Approximately half of the surveyed CPs (55.9\%) were not aware of the Health Authority in Abu Dhabi (HAAD) PV program in the UAE. This finding was reasonably similar to the observation made in Malaysia where about 59.3\% of the participants were not aware of the availability of PV center in their country [31]. On the other hand, the figures in the present study were lower than the figures reported in Saudi Arabia (86.8\%) [16], and far higher than figures reported in Holland and in UK [19, 32]. In Holland only (1\%) CPs were not aware of the availability of national PV Centre [19]. In UK (7\%) CPs were not alert about the existence of national PV program [32]. These results may point to inadequate program announcement to CPs which emphasizes on the urgency of developing strategies to increase the knowledge about PV center availability in the country.

In addition, the study findings had revealed that none of the pharmacists correctly defined the ADRs term and only $28(2.6 \%)$ of the pharmacists claimed to know the difference between ADR type1 and ADR type 2 , while in fact $15(6.7 \%)$ pharmacists were able to define correctly the difference. The finding of the study did not differ from studies in other countries [16, 31].

It was found in this current study that 186 pharmacists (83.4\%) do not know how to report ADRs. Similar findings have been reported in China [25] where majority of the participants were having poor knowledge on how to report ADRs. Unlike findings of other studies conducted at UK [26] and Australia [23] where the participants showed adequate knowledge on how to report ADRs. These findings advocate the need for awareness programs for the pharmacists about ADRs reporting. The awareness program should focus on the filling method of the ADRs form and the details of the reporting procedure.

Very often, the uncertainty about the causality between the ADRs and the drug was one of the reasons for under-reporting of ADRs [33]. Thus; it becomes necessary to make the pharmacists alert about how to perform the causality assessment for ADRs. One of the common scales used for causality assessment is the Naranjo algorithm [31]. The present study found that only one community pharmacist $(0.4 \%)$ was aware of the Naranjo algorithm, while another study showed that $30.3 \%$ of the participants were aware of Naranjo algorithm [31]. In this study, none of the CPs were aware of the severity assessment scale.

It can be ascertained that under-reporting of ADRs in UAE is not due to negative attitudes of the pharmacists themselves as the findings of the study reported a positive attitude of CPs towards ADRs reporting. The findings of the current study were parallel to other studies at UK $[14,23]$ where pharmacists showed a 
positive attitude towards ADRs reporting but different from the study done at New Zealand, where negative attitude was observed among pharmacists [27].

When it came to specific professions roles, 193 of the surveyed pharmacists $(86.5 \%)$ felt that CPs should be involved in ADRs reporting process; in addition, the study found that 199 of the respondents (89.2\%) believed that ADRs reporting is a part of the professional role of pharmacists. These results were much related to data reported for CPs in Saudi Arabia [16] where the vast majority of pharmacists (90\%) considered ADRs reporting a part of their professional role as pharmacist. On the other hand, outcomes from previous studies were stronger $[2,19]$ in which all the participants $(100 \%)$ considered ADRs reporting a part of the professional role of a pharmacist. CPs prime responsibility is ensuring patient safety which can be achieved by active and voluntary participation in the PV program. However, it is the responsibility of the PV center to keep up this positive attitude of the pharmacists, by informing them about the great value of reporting in morbidity and mortality reduction and by bringing up-to-date related PV news.

Although $\mathrm{MOH}$ did not want to receive reports of only proven ADRs, $94.5 \%$ of the pharmacists indicated that they must be sure of the causality between the drug and ADRs before reporting. This finding is consistent with previous findings reported about pharmacists in other countries like Saudi Arabia [16], which reflect the fear of the reporter of appearing unwise and irrational. This negatively-believed attitude should be addressed extremely in any informative workshops to alleviate pharmacists anxiety and to strengthen their clinical confidence in reporting ADRs.

It was disappointing that a negative sign was revealed by this survey as a large proportion of pharmacists $97.3 \%$ were not willing to report ADRs caused by the OTC. Unlike pharmacists in Saudi Arabia, where majority of them were willing to report ADRs related to OTC products [16]. This finding suggests urgent need to educate pharmacists about reporting guidelines and to encourage them to report all reactions for all drugs including new drugs, OTC and herbal products.

Another negative sign discovered in this study was that (96.9\%) CPs expressed their concerns for the need to discuss any suspected ADRs with a physician, even though they are not required to do so before submitting the report to HAAD PV center. The finding of the present study reflects the lack of confidence and fears of legal consequences. Similar findings were reported by previous surveys [16,19]. Discussion with physician concerning reporting ADRs by CPs should not be part of the program, since this may become an obstacle for reporting as well as pharmacist reliance on the physician judgment [16].

The positive attitude towards ADRs reporting has indicated that pharmacists were keen and eager to learn and practice if knowledge about ADRs reporting is conveyed to them and that they are sufficiently prepared and assisted. Their willingness was indicated by the fact that the majority $(86.1 \%)$ of the pharmacists were agreed to attend additional courses or workshops on PV with the purpose of improving their talent to spontaneously report ADRs.

The study showed that the practice score among the surveyed pharmacists were very low (11.2\%). In Malaysia only one pharmacist submitted ADR report to the regulatory authority [30]. The finding of this study has indicated very low participation (3.6\%) in reporting ADRs. Thus it was not surprising to find that only $0.9 \%$ of pharmacists claimed to report a new ADR for drugs and that only $2.7 \%$ had submitted ADRs reports related to OTC and herbal products.

One of the important findings revealed in the study was the positive correlation between Knowledge and attitudes towards ADRs reporting. Thus if the knowledge of ADRs reporting is improved then the pharmacists attitude will also improve which would be reflected on ADRs reporting schemes in a positive manner. In distinction, [16, 24, 26] reported poor knowledge level among pharmacists and positive attitude towards PV.

The present study has found association between knowledge and practice toward ADRs reporting. This finding is not parallel with a previous study [25] where the majority of respondents irrespective of their knowledge on ADRs reporting have never reported any ADRs to any place.

The present study discovered no significant relationship between attitude and practice towards ADRs reporting, meaning those participants who have never practiced reporting ADRs were likely to have an equal chance of having a positive attitude towards ADRs reporting. This finding is consistent with other findings [23, 36]. 


\section{CONCLUSION}

RECOMMENDATIONS: The PV HAAD center should make sure that all pharmacists are qualified and knowledgeable about PV and ADRs reporting. They have to make sure of the availability of the reporting forms by distributing them to the medical offices, community pharmacies, drug stores, hospitals and any other health providing system. The Ministry of Higher Education should find measures to review and improve pharmaceutical schools curricula to guarantee the incorporation of PV and ADRs reporting system conception. Pharmacy Council should include PV in continuous pharmaceutical education as a part of license requirements for pharmacists in UAE.

LIMITATIONS: The major limitation of this study is that the findings were restricted to only community pharmacists working in two cities in UAE, Sharjah and Ajman. The outcomes would have been more significant if the study was conducted in all UAE cities.

\section{REFRENCES}

[1] Gallagher RM, Kirkham JJ, Mason JR, Bird KA, Williamson PR, Nunn AJ, Pirmohamed M, Development and inter-rater reliability of the Liverpool adverse drug reaction causality assessment tool, PloS One,6(12),2011,e28096. doi: 10.1371/journal.pone.0028096.

[2] Elkalmi RM, Hassali MA, Ibrahim MIM, Widodo RT, Efan QM, Hadi MA. Pharmacy students' knowledge and perceptions about pharmacovigilance in Malaysian public universities, Am J Pharm Educ,75(5), 2011, Article 96.

[3] Kharkar M, Bowalekar S. Knowledge, attitude and perception/practices (KAP) of medical practitioners in India towards adverse drug reaction (ADR) reporting, Perspect Clin Res, 3(3), 2012, 90-94.

[4] Morimoto T, Gandhi TK, Seger AC, Hsieh TC, Bates DW. Adverse drug events and medication errors :detection and classification methods, Qual Saf Health Care, 13(4), 2004, 306-314.

[5] Nebeker JR, Barach P, Samore MH. Clarifying adverse drug events: a clinician's guide to terminology, documentation, and reporting, Ann Intern Med, 140(10), 2004, 795-801.

[6] Hodgkinson MR, Dirnbauer NJ, Larmour I. Identification of Adverse Drug Reactions Using the ICD-10 Australian Modification Clinical Coding Surveillance, Journal of Pharmacy Practice and Research, 39(1), 2009, 19-24.

[7] Patel KJ, Kedia MS, Bajpai D, Mehta SS, Kshirsagar NA, Gogtay NJ. Evaluation of the prevalence and economic burden of adverse drug reactions presenting to the medical emergency department of a tertiary referral centre: a prospective study, $B M C$ Clinical Pharmacology, 7(1), 2007, 7-8.

[8] Dormann H, Muth-Selbach U, Krebs S, Criegee-Rieck M, Tegeder I, Schneider HT, Geisslinger G. Incidence and costs of adverse drug reactions during hospitalization, Drug Saf, 22(2), 2000,161-168.

[9] Ernst FR and Grizzle AJ. Drug-related morbidity and mortality: updating the cost-of-illness model, J Am Pharm Assoc (Wash), 41(2), 2001, 192-199

[10] Stricker BH and Psaty BM. Detection, verification, and quantification of adverse drug reactions, $\mathrm{Br} \mathrm{Med} \mathrm{J,} \mathrm{329(7456),} \mathrm{2004,} \mathrm{44-}$ 47.

[11] Meyboom RH, Egberts AC, Gribnau FW, Hekster YA. Pharmacovigilance in perspective, Drug Saf, 21(6), 1999, 429-447

[12] Edwards IR and Aronson JK. Adverse drug reaction: Definitions, diagnosis and management, Lancet, 356,2000, $1255-1259$.

[13] Hazell L and Shakir SA. Under-reporting of adverse drug reactions, Drug Saf, 29(5), 2006, 385-396.

[14] Sweis D and Wong IC. A survey on factors that could affect adverse drug reaction reporting according to hospital pharmacists in Great Britain, Drug Saf, 23(2), 2000,165-172.

[15] Herdeiro MT, Figueiras A, Polnia J, Gestal-Otero JJ. Physicians Attitudes and Adverse Drug Reaction Reporting, Drug saf, 28(9), 2005, 825-833.

[16] Bawazir SA. Attitude of community pharmacists in Saudi Arabia towards adverse drug reaction reporting, Saudi Pharm J, 14(1), 2006, 75-83.

[17] Aziz Z, Siang TC, Badarudin NS. Reporting of adverse drug reactions: predictors of under-reporting in Malaysia, Pharmacoepidemiol Drug Saf, 26(2), 2007, 223-228.

[18] Gavaza P, Brown CM, Lawson KA, Rascati KL, Wilson JP, Steinhardt M. Influence of attitudes on pharmacists' intention to report serious adverse drug events to the Food and Drug Administration, Br J Clin Pharmacol. 72(1), 2011,143-152.

[19] Van Grootheest AC, Van Puijenbroek EP, De Jongvan den Berg LTW. Contribution of pharmacists to the reporting of adverse drug reactions, Pharmacoepidemiol Drug Saf, 11(3), 2002, 205-210.

[20] Herdeiro MT, Polnia J, Gestal-Otero JJ, Figueiras A. Improving the Reporting of Adverse Drug Reactions, Drug Saf, 31(4), 2008, 335-344.

[21] American Society of Health-System Pharmacists. ASHP guidelines on adverse drug reaction monitoring and reporting, Am $J$ Health Syst Pharm, 52,1995, 417-419.

[22] Toklu HZ and Uysal MK. The knowledge and attitude of the Turkish community pharmacists toward pharmacovigilance in the Kadikoy district of Istanbul, Pharm World Sci, 30(5), 2008, 556-562.

[23] Green CF, Mottram DR, Rowe PH, Pirmohamed M. Attitudes and knowledge of hospital pharmacists to adverse drug reaction reporting, Br J Clin Pharmacol, 51(1), 2001, 81-86.

[24] Hasford J, Goettler M, Munter KH, Mller-Oerlinghausen B. Physicians' knowledge and attitudes regarding the spontaneous reporting system for adverse drug reactions, J Clin Epidemiol, 55(9), 2002, 945-950.

[25] Li Q, Zhang SM, Chen HT, Fang SP, Yu X, Liu D, Zeng FD. Awareness and attitudes of healthcare professionals in Wuhan, China to the reporting of adverse drug reactions, Chin Med J (Engl), 117(6), 2004, 856-861.

[26] Evans SM, Berry JG, Smith BJ, Esterman A, Selim P, OShaughnessy J, Dewit M. Attitudes and barriers to incident reporting: a collaborative hospital study, Qual Saf Health Care, 15(1), 2006, 39-43.

[27] Zolezzi M and Parsotam N. Adverse drug reaction reporting in New Zealand: implications for pharmacists, Ther Clin Risk Manag, 1(3), 2005, 181-188.

[28] Raosoft Sample Size Calculator. 2012. Available from URL: http: //www. raosoft. com/samplesize.html. Accessed Dec 2012.

[29] Vessal, G, Mardani Z, Mollai M. Knowledge, attitudes, and perceptions of pharmacists to adverse drug reaction reporting in Iran, Pharm World Sci, 31(2), 2009, 183-187. 
[30] Ting KN, Stratton-Powell DM, Anderson C. Community pharmacists views on adverse drug reactions reporting in Malaysia: a pilot study, Pharm World Sci, 32(3), 2010, 339-342.

[31] Palaian S, Ibrahim MI, Mishra P. Health professionals' knowledge, attitude and practices towards pharmacovigilance in Nepal, Pharmacy Practice (Internet), 9(4), 2011, 228-235.

[32] Green CF, Mottram DR, Raval D, Proudlove C, Randall C. Community pharmacists' attitudes to adverse drug reaction reporting, Int J Pharm Pract, 7(2), 1999, 92-99.

[33] Irujo M, Beitia G, Bes-Rastrollo M, Figueiras A, Hernndez-Diaz S, Lasheras B. Factors that inuence under-reporting of suspected adverse drug reactions among community pharmacists in a Spanish region, Drug Saf, 30(11), 2007, 1073-1082.

[34] Pirmohamed M, James S, Meakin S, Green C, Scott AK, Walley TJ, Breckenridge AM. Adverse drug reactions as cause of admission to hospital: prospective analysis of 18820 patients, $\operatorname{Br}$ Med J, 329(7456), 2004, 15-19.

[35] Amit D and Rataboli PV. Adverse drug reaction (ADR) noti_cation drop box: an easy way to report ADRs, Br J Clin Pharmacol, 66(5), 2008, 723-724.

[36] Oshikoya KA and Awobusuyi JO. Perceptions of doctors to adverse drug reaction reporting in a teaching hospital in Lagos, Nigeria, BMC Pharmacol Toxicol, 9(1), 2009, 9-14. 